Artículos

\title{
La prensa de costumbres y la literatura de civilidad en la Buenos Aires tardocolonial
}

The customs press and the literature of civility in late colonial Buenos Aires.

Matias Maggio-Ramirez

DOI: https://doi.org/10.24215/23468971e118

Universidad Nacional de Tres de Febrero, Argentina

mmramirez@untref.edu.ar

(D) http://orcid.org/0000-0002-1106-1381

Recepción: 22 Enero 2020

Aprobación: 27 Abril 2020

\section{Resumen:}

Analizar cómo la prensa de costumbres tardocolonial abordó la literatura de civilidad, para cuestionar la educación familiar. Se puso de manifiesto la necesidad de habitar, tanto el campo como la ciudad, de acuerdo a los tiempos modernos. Se recopiló, contrastó y analizó una selección de artículos que abordaban la crítica de costumbres en los periódicos de los primeros años del siglo XIX. Se evidenció el cuestionamiento por parte de la élite criolla de las tradiciones, la educación particular y la transmisión generacional del saber. Se buscaba lograr un cambio en las costumbres, mediante la cultura impresa, para que Buenos Aires no sea "el fiero lunar de las provincias cultas", como escribió Francisco Cabello y Mesa, del imperio borbónico.

Palabras Clave: Civilidad, Costumbres, Virreinal, Prensa, Educación.

\section{Abstract:}

Analyze how the late colonial customs press approached the literature of civility, to question family education. The need to inhabit both the country and the city was revealed, according to modern times. A selection of articles addressing the criticism of customs in the newspapers of the first years of the 19th century was compiled, contrasted and analyzed. The questioning by the Creole elite of traditions, private education and the generational transmission of knowledge was evident. It sought to achieve a change in customs, through the printed culture, so that Buenos Aires is not "the fierce moon of the educated provinces", as Francisco Cabello y Mesa, of the Bourbon empire wrote.

KEYWORDS: Civility, Customs, Viceroyalty, Press, Education.

\section{LA PRENSA DE COSTUMbres}

La literatura de civilidad o literatura de cortesía tiene como "objetivo definir en qué consisten los buenos modales y el comportamiento civilizado [para] prescribir sus reglas” (Bolufer Peruga, 2019, p. 125) que cuestionaban el pasado e instauraban un meta de llegada para habitar la ciudad, a través de distintos géneros discursivos y soportes materiales. Los periódicos que abordaron la crítica de costumbres y los libros sobre educación moral, poblaron las bibliotecas de la élite letrada porteña entre finales del siglo XVIII y principios del XIX (Peire, 2008; Torre Revello, 1965; Furlong, 1944). Se buscaba en sus páginas enseñar cómo habitar y vivir en el mundo moderno (Goldgel, 2013). Las reformas borbónicas, con el nombramiento de Buenos Aires como sede del virreinato del Río de la Plata, marcaron el auge de la prensa impresa que tuvo como públicos a comerciantes, burócratas, militares, clérigos, profesionales y artesanos (Martini, 1998; Martínez Gramuglia, 2008). Las investigaciones sobre la prensa de principios del XIX se centraron en el pensamiento agrario y económico (Martínez Gramuglia, 2009; Pastore y Calvo, 2005; Lafit, 2017), así como la constitución de la figura del intelectual (Díaz, 2005) o la historia natural (Navallo, 2011). Los estudios sobre la prensa iberoamericana del siglo XVIII y XIX, últimamente, comenzaron a analizar la crítica de costumbres como una forma de educación en el arte de vivir (Bolufer Peruga, 2019; Maggio-Ramírez, 2017), así como la educación de oficios mecánicos (Arata, 2010). La relación entre la crítica de costumbres, la literatura de 
civilidad y la transmisión del saber es todavía un área todavía a explorar, y más si tienen como principales fuentes el Telégrafo Mercantil, Rural, Político, Económico e Historiográfico del Río de la Plata (1801-1802) y el Semanario de Agricultura, Industria y Comercio (1802-1807). En cambio la educación formal durante el período tardocolonial fue abordado desde la recopilación y análisis de fuentes realizada por Juan Probst (1924) hasta los estudios pioneros de la educación de primeras letras en la campaña bonaerense, con fuentes del Archivo Histórico de la Provincia de Buenos Aires, de Juan Bustamante Vismara (2000) que le permitió reconstruir la cotidianidad del aula. En ellas circularon dísticos y catecismos, tanto religiosos como políticos. Los primeros "remite[n] al refranero popular, y en tanto fórmulas de fácil memorización para su transmisión oral, estos pequeños tratados de moral y buenas costumbres demostraron durante siglos sus virtudes didácticas, todavía en el cruce entre oralidad y escritura [...]" (Cucuzza, 2002, p. 57). La estructura del catecismo centrada en preguntas y respuestas fue utilizada por Vieytes en sus lecciones de agricultura. Esa propuesta de lectura no necesitaba de un saber experto sobre la agricultura, por ejemplo, sino que tan sólo se pudiera leer el texto en voz alta para favorecer la memorización y luego corregir las respuestas exactas.

Los impresos ibéricos, en una actitud paternalista, tenían la responsabilidad frente a "los ciudadanos en su tarea ilustrada y civilizadora" (Labrador y De Pablos, 1989, p. 48), por lo tanto fueron una figura tutelar para la prensa porteña que transcribió con ahínco lo que se publicó desde el Correo Mercantil de España y sus Indias hasta el Semanario de Agricultura y Artes dirigido a los párrocos (Maggio-Ramírez, 2008; 2020). Aquí se rastreará la emergencia de la literatura de civilidad en la prensa de principios del siglo XIX en la crítica de las costumbres. Juan Hipólito Vieytes cuestionó en el "Prospecto" de su periódico la pervivencia de saberes tradicionales y orales que se transmitían generacionalmente entre los campesinos y labradores porque los consideraba propio del pasado. Para romper con la circularidad de los saberes que se repetían entre generaciones, apelaba a la medicación lectora del "ciudadano patriota" y del "párroco ilustrado", que abandonarían la ciudad para leer las páginas de la prensa en la campaña bonaerense, según la ficción enunciativa que hizo explícita en el "Prospecto" (SAIC, 1928, pp. III-VIII)

\section{LA LITERATURA DE CIVILIDAD Y LA TRANSMISIÓN DEL SABER}

La transmisión generacional fue puesta en tela de juicio por los lectores del Telégrafo, quienes enviaron cartas al periódico para sostener los beneficios de la educación en las escuelas de primeras letras. El 23 de mayo de 1801 se publicó en el Telégrafo unas las líneas remitidas y firmadas con las iniciales "P.J.F.C.", probablemente era Pedro Juan Fernández, con el título "Educación”, en tres entregas que buscaban fomentar la "felicidad de la patria”. La finalidad del artículo era cuestionar los saberes populares, la transmisión oral, que sucedía dentro del ámbito familiar, por considerarla propia del pasado. En cambio se buscaba apostar por la educación, centrada en la razón utilitaria, ilustrada cuyo conocimiento emanaba de una fuente impresa con el poder de extirpar las costumbres erradas, los vicios y las supersticiones que se transmitían generacionalmente. El autor sostuvo que la educación pública, caracterizada como encarnación de la cultura letrada, servía para “corregir y borrar aquellas erróneas Ideas del bien y del mal, que por la ignorancia, o desidia de los Padres, y por la superstición de las Madres, se comunican a los hijos en su infancia" (TM, 1914, p. 159). El lector del Telégrafo argumentó que si el progreso le había permitido al hombre el dominio "[...] sobre el mundo físico: ¿por qué motivo no podremos nosotros esperar alguno sobre el mundo moral?”, por lo que fomentaba desterrar en los niños las ideas que aprendieron por "ignorancia o desidia de los padres, y por la superstición de las madres". Citaba a Cicerón, Séneca y la Biblia al afirmar que "[l]a educación está casi enteramente fundada sobre la imitación. No se necesita otra cosa que poner buenos modelos, para formar las copias”. Esta perspectiva reproductivista implicaba que al niño, como si fuera una superficie de cera, se le podían imprimir "todas las buenas cualidades que observa". El escritor de la correspondencia al Telégrafo concluyó con la promesa de ocuparse "útilmente el tiempo, en desterrar de nuestros escritos y de nuestra patria las 
opiniones, las preocupaciones y aquellas frivolidades que solo producen viento de fama hinchada en el vulgo imbécil” (TM, 1914, p. 168).

La transmisión generacional de los saberes artesanales, las vanidades y la ignorancia de la plebe se presentaba como parte de un panorama aciago que tendería a reproducirse si la luz de la razón no se inmiscuía mediante la enseñanza pública. A pesar de las dificultades que se encontraban en la educación para "el espacio público" acorde a la urbanidad y a la civilidad, era "más fácil, más útil y más eficaz que la privada". El autor contaba con tal certeza porque extrapolaba la confianza en el progreso de las ciencias naturales al ámbito de lo social. La "educación privada" no era aquella que brindaban a sus vástagos la élite letrada. Al caracterizar la educación familiar como ejemplo de la desidia y la superstición dejaba en claro que no eran sus pares. La otredad dentro de la ciudad letrada (Rama, 1998) estaba marcada por su distancia con la cultura impresa y las posibilidades de su apropiación.

Desde Oruro, Eugenio del Portillo envió un artículo sobre la utilidad de los periódicos y su particular escrutinio de los números recibidos a Francisco Cabello y Mesa, editor del Telégrafo Mercantil. Portillo aprovechó para desplegar su erudición en el conocimiento de la literatura europea dieciochesca. La recorrida del Telégrafo fue minuciosa. Desaconsejó la lectura de la carta enviada al periódico por "P.J.F.C." con el título de "Educación" el 23 de mayo de 1801 (TM, 1914, p. 151). Esas líneas tuvieron la intención de dictar instrucciones para la felicidad del hombre, según Portillo, por lo que redujo sus ideas a "unas pocas reflexiones" sobre un "[...] asunto demasiado general y trillado por máximas indeterminadas sin encontrarse a censurar los obstáculos y vicios morales y físicos de educación más notables en la América y Buenos Aires" (TM, 1914, p. 443). El abogado cordobés no creía que la educación doméstica fuera "un trabajo raro y difícil, aún para un padre dotado de todas las virtudes” (TM, 1914, p. 152), como sostenía P.J.F.C (problemente Pedro Juan Fernández). Mientras que ese artículo criticaba a los padres, por su desidia y superstición, en el de Portillo se lo imaginaba dotado no de una sino de todas las virtudes.

El erudito cordobés, radicado en Oruro, recordó que, en territorio del virreinato, “[...] corren con mucha aceptación y crédito los dos tomitos del Sr. Rosell sobre La educación, conforme a los principios de la religión christiana, leyes y costumbres de la nación española; fuera de innumerables preciosas traducciones de las lenguas vulgares, asegurando el Abate Andrés que ya fastidian tantos libros de esta materia” (TM, 1914, p. 443). El auge de la literatura de civilidad y de educación moral en el siglo XVIII español fue señalado por el abate Juan Andrés en su Origen, progresos y estado actual de toda la literatura. El apogeo de ese género literario se caracterizó, en la particular mirada del abate, por la falta de originalidad en los libros de educación y “[...] aún tratando materias tan importantes llegan a enfadar por su excesiva copia” (Andrés, 1784, p. 414). La interpretación y reescritura, así como la copia, de la literatura de civilidad en el periódico porteño era un signo más de los intereses de los lectores virreinales sobre las buenas costumbres. El abate Andrés incluyó los romances morales entre los libros de educación, porque podían contribuir a corregir defectos para iluminar el camino a la virtud. Así como los romances fueron "condenados en otros tiempos por los severos filósofos como una lectura muelle y lasciva, han llegado a ser ahora una escuela de honestidad y de sabiduría, y pueden mirarse como lecciones de la más austera y pura moral" (Andrés, 1787, pp. 500-501). Al analizar catálogos y bibliografías españolas de finales del siglo XVIII, investigaciones recientes, encontraron un abundante número de publicaciones sobre educación, desde una mirada amplia, ya que

[...] incluían reflexiones pedagógicas de carácter general, tratados educativos diferenciados según el sexo o condición social de sus destinatarios (para la educación de los niños, de las mujeres, de la nobleza, de los artesanos...), textos de educación física, compendios de saberes para su uso escolar, memorias sobre temas pedagógicos para su discusión pública en sociedades y academias u obras de ficción (novelas, teatro) con un propósito explícitamente didáctico (Bolufer, 2002, p. 8).

Eugenio del Portillo no necesitaba, entonces, explayarse sobre cuánto favorecía la educación pública a la sociedad, porque los argumentos eran conocidos por los lectores que imaginaba tenía el Telégrafo. ${ }^{1}$ Los libros que circulaban en América eran en su mayor parte traducidos e impresos en España. La calidad de la literatura 
de civilidad traducida al español fue puesta en duda tanto por Portillo cuanto por el bibliógrafo español Juan Sempere y Guarinos, en su Ensayo de una biblioteca española de los mejores escritores del reinado de Carlos III, al escribirsobre la obra de Rosell. Sempere (1789, p. 64) dudó de la excelencia de las obras extranjeras sobre educación y urbanidad, ya que fuera de España "[...] se han publicado varios tratados, acerca de la educación, ya en general, ya determinada a diferentes clases. Nosotros, después de los Leones, Ribadeneyras, Saávedras, Gracianes, Marques, [...] descuidamos de este ramo de literatura, contentándonos con traducir algunas obras extranjeras y no las mejores".

El bibliógráfo español, al igual que Portillo, recomendaba el libro de Rosell. A diferencia de la propuesta de "P.J.F.C." en el Telégrafo, Rosell sostuvo que la educación habría de estar a cargo de los padres, como lo expresaba en el primer tomo de su obra. Eran los padres que con acceso a la cultura impresa, a diferencia de aquellos que se dejan ganar por la superstición y la desidia, debían guiar al niño dentro de los principios cristianos y en el trato humano "que les han de ir inspirando; y el modo con que esto debe practicarse por medio de la conversación, juegos y entretenimientos" (Sempere y Guarinos, 1789, p. 65). Esta idea fue recuperada por la recomendación de Portillo en su escrutinio sobre el Telégrafo, y tiempo después sería destacada por otro vecino del Alto Perú, Gabriel Hevia y Pando, en el Semanario de Vieytes, cuando cuestionaba la cultura escrita como la mejor forma de enseñar nuevos métodos de labranza a los hijos de campesinos. Es decir, en el Telégrafo aparecieron los primeros indicios de discusiones pedagógicas sobre la efectividad de la transmisión del saber a través de la escritura o de la oralidad, pero sin dejar de pensar la instancia de aprendizaje como si fuera una recepción pasiva donde sólo se reproduce una regla impuesta. También se dejaba en claro que no todos los padres podían educar en casa, aún con el auxilio de la literatura de civilidad o educación moral porque no estaban preparados. Estaban anclados en el pasado y allí se apelaba a las escuelas de primeras letras (Caruso, 2010; Maggio Ramírez, 2007)

\section{De la ciudad al campo. Ficciones de lectura}

La consigna que recorrió la mayor parte del Semanario de Agricultura se centró en abandonar las erradas prácticas del pasado, tanto para los labradores como para el ciudadano encerrado en su gabinete citadino. Para dejar el pasado de lado, nada podía "contribuir con más eficacia a este fin que la publicación de un periódico" que sería el medio para propagar los conocimientos, aunque "sería casi del todo insuficiente [... sin] el celo conocido de nuestros párrocos", escribió Vieytes en el "Prospecto" (SAIC, 1928, pp. III-VIII). El desconocimiento de las modernas técnicas agrícolas era una de las causas por las que los labradores mantenían una economía de subsistencia. En cambio, al igual que sostuvieron los teóricos de la Ilustración escocesa, si se adquirían los nuevos saberes podrían ampliar su producción para industrializarla y así incorporar nuevos "frutos del país" en las redes comerciales. La lectura del Semanario, sostuvo Vieytes, inflamaba el corazón del labrador para sacarlo de la inacción y el letargo en el que se hallaba sumido. La prosperidad en aquellas poblaciones situadas en terrenos ingratos, condenadas a la miseria e indigencia, se podía lograr gracias al "auxilio y del socorro de todos aquellos que amantes a la patria aspiran a la general felicidad de estas provincias" (SAIC, 1928, pp. III-VIII). Al igual que el Telégrafo, que intentó llevar adelante la sociedad patriótica, se buscó la complicidad de los lectores como actores necesarios para lograr la felicidad del pueblo.

El perfil pedagógico del Semanario se puede caracterizar a partir del "Prospecto", donde se esperaba que los estrechos límites de los conocimientos del labrador se pudieran ensanchar gracias al interés que el ciudadano instruido y el párroco tendrían en enseñarle. Los preceptos serían "más sencillos” para que pueda el labrador llevarlos a la práctica. La propuesta de Vieytes tenía como finalidad lograr la transformación de las campañas "lúgubres" y "desiertas" en un "jardín ameno y delicioso", en tanto reactualización del tópico renacentista del locus amoenus. Mientras que el Telégrafo se centró en las buenas costumbres urbanas, como la educación del comerciante, en el Semanario se hizo hincapié en el labrador, pero con un rodeo sobre los deberes del ciudadano y acerca de cómo debía aportar en favor de la felicidad y prosperidad. Es decir, mientras que 
el Telégrafo cuestionaba el honor del comerciante y la virtud de las damas; en el Semanario se apelaba al "ciudadano patriótico" para que cumpliera con su deber en los tiempos ilustrados. No se interpelaba a los ciudadanos desde la carencia o la imprudencia de sus costumbres, sino desde el deber ser, por lo que se instalaba en el futuro aquello a corregir y no se cuestionaba el presente, como sí lo hacía Cabello y Mesa respecto de los porteños.

En el Semanario, se consideraba a la agricultura "capaz por sí sola de aumentar la opulencia de los pueblos hasta un grado casi imposible de calcularse [...]" (SAIC, 1928, p. 1). La agricultura no sólo era "el principal apoyo de la sociedad", sino que constituía igualmente "el origen de las luces adquiridas por el hombre civilizado, y sin ella aún se hallaría el hombre envuelto entre las costumbres más feroces; confinado a vivir entre las fieras en la espesura de los bosques"( $S A I C, 1928$, p. 2). Para que el labrador pudiera mudar su práctica errada, derivada de sus padres, y así cambiar su situación de subsistencia, era necesaria la unión de "la teoría a la práctica".

Desde el "Prospecto" del Semanario se cuestionó que los saberes botánicos y agrarios se encontraran encerrados en un gabinete, donde el ciudadano erudito se formaba en silencio, sin difundir "aquellos conocimientos que adquirió, y que unos libros tan útiles se hallen solo circunscriptos a la pequeña esfera de un estante". La apuesta de Vieytes era que los labradores cambiaran su "práctica errada", que había sido transmitida generacionalmente por vía de la experiencia y la oralidad, gracias a la mediación de los saberes de la cultura impresa por parte del "ciudadano patriota". ${ }^{2}$ Desde el gabinete donde se examinaba la naturaleza "por menor", se proponía su difusión "al medio de la campaña, en donde la estudia en grande siguiéndola los pasos, y sorprendiéndola por decirlo así en el acto mismo de sus operaciones” (SAIC, 1928, p. 3). El conocimiento del erudito, que mudaba de escala, haría que el campesino pudiera prosperar al dejar de lado los saberes heredados, "recibidos ciegamente de sus mayores". El apoyo de las sociedades patrióticas dedicadas al fomento de la "agricultura interior" fue, en la propuesta del Semanario, el principal sostén para el crecimiento de la actividad que se encontraba "entre los primeros pañales de su infancia".

Ante la ausencia de recursos minerales, que eran el principal activo de la zona del Alto Perú, se contrapuso la pampa como fuente "inagotable" de los tesoros ligados a la agricultura y ganadería. La campaña bonaerense fue representada como cuna de la abundancia, donde reinaba el silencio, la sencillez, la inacción, el adormecimiento así como "la ociosidad y la holgazanería, que traen consigo aquellos vicios vergonzosos que degradan a la razón y que conducen precipitadamente al hombre hacia la mendiguez [...]”. El ciudadano orgulloso y altivo, de palabras complicadas, escaparía del bullicio de la ciudad para brindar sus conocimiento al labrador. En ese gesto, lo despertaría de su inacción para evitar que caiga en el ocio. El ciudadano, al obtener del labrador "aquel aire de sencillez que se desconoce en las grande poblaciones", declinaría "la ferocidad de un genio altivo y dominante" (SAIC, 1928, p. 4). El labrador “no temerá de ver a su lado al ciudadano". Ya desde el primer número, el Semanario planteaba la escena ficcional de comunicación entre el ciudadano y el labrador como una instancia de conflicto que sería resuelta en beneficio mutuo. El campesino saldría del círculo de la economía de subsistencia para entrar en la dinámica urbana y consumir las mercancías que desconoce. Vieytes apelaba al labrador para que llegase al máximo de su potencial con su trabajo y así pudieran exportar los excedentes que permitieran el “[...] goce de innumerables bienes que ahora no disfruta, ni desea: se despertará en su corazón aquel deseo de aumentar sus comodidades, y de ensanchar sus posesiones, y transmitiéndose de padres a hijos esta gloriosa emulación [...]" (SAIC, 1928, p. 7). Ya no sería aquel trabajador en una economía de estrechez y subsistencia, sino que se encaminaría a gozar del fetichismo de la mercancía. La influencia del ciudadano en el campo se planteaba para que, tras cubrir sus necesidades, se pueda "surtir el gusto y alimentar asombrosamente el lujo" (SAIC, 1928, p. 7).

El número siguiente del Semanario se dedicó a analizar los aportes que podrían realizarse desde la industria para el fomento de ramos poco usuales de la agricultura, que tenían un alto potencial en su comercialización. Los procesos de industrialización del campesinado, al dar "valor a los frutos que cultiva la agricultura", promoverían el bienestar general tanto como la "ocupación y sustento", "la abundancia y las riquezas, [...] 
la población y los consumos, [...] la ciencia y las artes”. Este cambio tendría la fuerza para desterrar la mendicidad, así el pueblo podría salir "de pobre, bárbaro e ignorante" (SAIC, 1928, p. 10). Por ejemplo, para lograr esa meta se consideraba de vital importancia la siembra del lino y el cáñamo, así como el "árbol del añil", a partir de cuyo fruto se daba color a las telas. ${ }^{3}$ Vieytes dejó en claro, tanto en el "Prospecto" como en los primeros números, que sería "el órgano por donde se transmita al común del pueblo toda especie de conocimientos para que se proceda al fomento y cultivo de los reglones insinuados, y de otros muchos que sucesivamente tendré cuidado de notar" (SAIC, 1928, p. 15). El saber ilustrado recorrería el camino del centro escriturario a la periferia, pero mediado por el ciudadano y el párroco, "a cuyo cuidado y vigilancia se halla encargada la conducta espiritual de estos preciosos miembros de la sociedad" (SAIC, 1928, p. 15). Los labradores serían inflamados por ciudadanos y párrocos para desterrar la inacción y la pereza. Números después, cuando Vieytes publicó los motivos que dificultaban la supervivencia del periódico, destacó el silencio de los actores que había supuesto a su favor, ya que desde el "Prospecto" se confesó "insuficiente por mí solo para llenar" los tópicos del Semanario, tanto para enviarle noticias útiles como para comunicar en la campaña las que ya se habían publicado (SAIC, 1928, p. 290). "El práctico agricultor ha enmudecido [...]", "el hacendado ha guardado un silencio profundo [...]", "el comerciante ha creído indigno de su atención [...]" y el párroco fueron parte de quienes "no han querido ocupar un cuarto de hora en leer un pliego de papel con el título de Semanario de agricultura" (SAIC, 1928, p. 290). La escena ficcional de lectura colectiva no se llevó a la práctica, por lo que el editor no dudó en cuestionar a los lectores que interpeló desde las primeras páginas del periódico.

La prensa era el vehículo para que el erudito estableciera lazos con los párrocos y ciudadanos ilustrados, dispuestos a dejar de lado el bullicio y desdén propio de la vida urbana frente a los labradores para comunicar los saberes europeos en favor de lograr la felicidad de los pueblos. Por ello, la representación del letrado anudado al territorio donde vive y con una conciencia en favor del bien común contrastó con el "gramático filósofo" propio del saber escolástico y barroco.

\section{Crítica de costumbres}

Pedro Juan Fernández y Almada, con el seudónimo Infausto Pastor, escribió una carta desde la campiña montevideana al Telégrafo. Las líneas, publicadas el $1^{\circ}$ de julio de 1801, proponían la enseñanza pública de la religión para "apresurar cuando antes el remedio de tantos males [...]", entre los que se contaban los robos, la embriaguez, el juego, los "más horribles pecados de sensualidad", la pereza y la holgazanería, encarnada en "aquella numerosísima turba de hombres perjudiciales sin domicilio, sin ocupación, sin religión, sin sentimientos de racionalidad [...]" (TM, 1914, p. 244). En la carta siguiente, sugirió que los estancieros construyeran oratorios donde se pudiesen congregar los campesinos a escuchar misa y aprender los dictados de la religión en favor de dulcificar las pasiones. Una vez más, el campo se construyó en oposición a la ciudad en las páginas del Telégrafo. El campo era el lugar de la falta, donde reinaba "la más triste soledad" y se estaba "rodeado de los objetos más lastimosos" en un "desierto" campero que era habitado por el "hombre rústico". En la carta posterior, del 1 de agosto, el Infausto Pastor creyó que los campesinos, por no contar con capillas cerca, no sabían persignarse y morían como bestias. La "relajación de las costumbres" implicaba que éstas se hallaban "pervertidas y sin regla alguna moral” en la campaña (TM, 1914, p. 325). El rol del sacerdote ilustrado, más allá de las escenas ficcionales de la enseñanza pública en el púlpito de las lecciones de agricultura modernacomo propuso Vieytes, se encontraba ligado al fomento de la civilidad para erradicar los males de la campiña (Di Stefano, 2000 y 2004; Barral, 2007). El clero ilustrado, además de los rudimentos de la religión, impartiría también "[...] la idea de civilización y reforma de costumbres [porque] aparece unida a la de cristianización, al menos en los primeros intentos de control de los rústicos pobladores de la pampa bonaerense" (Barral, 2007, p. 137). 
Las iniciativas en el fomento de la enseñanza elemental en la campaña "partieron de algunos de los benefactores de las iglesias rurales y de los propios párrocos, quienes podían exhibirlas entre los méritos en el ejercicio del ministerio parroquial". La apuesta por la educación de primeras letras buscaba disciplinar y controlar más eficazmente a la población rural. (Barral, 2007, p. 144). La proposición del Infausto Pastor se insertaba en la renovación ideológica de finales del siglo XVIII, que

concibe un pueblo bárbaro, víctima ignorante de sus malas costumbres y poco laborioso, destacando la necesidad de reunir a la población para civilizarla, así como superar su rusticidad y la caída en el delito inevitablemente asociada con ella, para hacer útil al Estado y a la Iglesia esa muchedumbre entregada a la embriaguez, al latrocinio, la bribonería, la mendicidad y otros crímenes. (Barral, 2007, p. 150)

El Telégrafo fue la caja de resonancia en que se criticaban las malas costumbres y se propugnaba la educación para la civilidad de la población. El 24 de junio de 1801, con la firma de "La porteña", se publicó en el periódico del extremeño una carta que criticaba el tono misógino de Fernández y Almada (el Infausto Pastor), que " [s] e aparta de aquella condescendencia ingeniosa que acostumbra el hombre fino a dorar nuestros defectos, haciéndonos creer que son virtudes; nos presenta culpables de los dolorosos progresos de la epidemia de viruela" (TM, 1914, p. 227)en Montevideo. "La porteña" se sintió molesta porque las palabras de Fernández le sonaron como "una grosería" y un "insulto" cuando solicitó al editor del Telégrafo que les "[...] predique y persuada a entrar por el sistema utilísimo de la inoculación" y por sostener que sólo las mujeres eran contrarias a esta práctica medicinal. La autora recriminó a Fernández que hubiera perdido de vista que “[...] el marido no carece de autoridad absoluta sobre sus hijos, y que al hombre siempre dominante, le sobra entereza para hacer su gusto aún en aquellas cosas que tocan en lo más vivo de nuestro amor propio" (TM, 1914, p. 228). La porteña dada a la escritura pedía a Fernández que dirigiese "sus lamentos clamorosos a los padres de los muertos, y no a las madres, que amas son capaces de oponerse a las determinaciones racionales del marido" (TM, 1914, p. 228). La anónima corresponsal exigió, en nombre de todas las damas, a Cabello y Mesa que "se digne encargarle la moderación y urbanidad con el bello sexo" (TM, 1914, p. 228) en los textos que publica.

Pocos días después, el 15 de julio de 1801, se publicó una carta enviada desde Montevideo que cuestionaba un artículo de Pedro Juan Fernández que insinuaba que las madres no inoculaban a sus hijos contra la viruela. La carta reivindicatoria, firmada con las iniciales C.M.M., de Cristóbal Martín de Montúfar,sostuvo que al tener Montevideo una "reciente y corta población, que aún le imposibilita establecer muchos reglamentos útiles de policía, ha logrado la inoculación una aceptación no menor, que la que ha podido conseguir en ciudades, que se tienen por más civilizadas” (TM, 1914, p. 272). ${ }^{4}$ Tanto Buenos Aires como Montevideo eran ciudades que medían su civilidad por contraste con la de distintas urbes del imperio español, que eran vistas como una meta de llegada.

La tensión entre racionalidad y religiosidad quedó en evidencia cuando se esgrimió, entre las causas por las que las madres no inoculaban a sus hijos contra la viruela, el que fueran presas de una "crasa ignorancia, que radicándolos en el fanatismo, les hace creer, como principio de religión, la fatal ilusión de que no deben causar tal enfermedad, sino esperar a que Dios la envíe." (TM, 1914, p. 272). No alcanzaba que el protomédico de Montevideo argumentara que la inoculación contaba con "su mayor apoyo en la religión cristiana", ni que el rey hubiese inoculado a sus propios hijos (TM, 1914, p. 272). Era completamente "inútil una persuasión, que solo consista en amontonar ejemplares. Todos los días salen a la luz papeles, que publican estos hechos a millardas". En Buenos Aires, también plagada de "ignorantes, e insensatos", se había esparcido algún informe que sólo logró que se derramaran " [...] tristes lágrimas a consecuencia de sus malditos, y descabellados consejos" (TM, 1914, p. 273). El orgullo local se había herido, "es una especie de calumnia" sostener la poca aceptación de la vacuna cuando no se habían enfermado quienes fueron inoculados, por lo que se enviaba la carta al Telégrafo en búsqueda de reivindicación. La falta de civilidad, al cuestionar los métodos científicos de la vacuna antivariólica, y el furor religioso eran leídos entre los letrados virreinales como una mácula que 
había que limpiar para que la ciudad volviera a brillar, y con ello sus habitantes ilustres. Así se restablecería el orden para evitar que la ciudad fuese considerada tan bárbara como el campo.

Pedro Juan Fernández no se quedó sin empuñar su pluma desde Montevideo frente a la escritora porteña y publicó su descargo el 29 de julio en el Telégrafo. En pocas palabras, apeló al tópico de la irracionalidad femenina para degradarla como contendiente discursivo, al sostener que "[n]o hay ira peor que la de la mujer", por lo que hará "lo que hace todo marido prudente, a quien nada le sirven todos sus calzones, cuando da con mujeres de esta clase" (TM, 1914, p. 304). El diccionario de la RAE de 1780 recuperó la expresión "ponerse o calzarse los calzones" para expresar "que se dice de la mujer que todo lo manda en su casa sin hacer caso de su marido", por lo que Fernández prefería no darle entidad a la carta firmada por la porteña. Al evitar confrontarla no la reconocía intelectualmente, más aún cuando afirmaba consolarse "con el elogio de V. hace de mi patriotismo, y con el de los hombres sensatos", por lo que otra vez le negaba la sensatez y la cordura al género femenino.

Fernández esperaba que se "abra la comunicación de los mares" para que el Telégrafo llegase a los "sabios del antiguo continente”. Imaginaba que, tras su lectura, exclamarían: “[...] Los pueblos que poco ha teníamos por bárbaros, tratan con el más vivo interés la conservación de nuestra especie [...]" (TM, 1914, p. 304), mientras Europa estaba convulsionada. El europeo ficcional de la carta de Fernández reconocería que "los pueblos del sur establecen nuevos Telégrafos para comunicarse recíprocamente aquellos conocimientos, que pueden ser útiles a sus semejantes" (TM, 1914, p. 304). La prensa era considerada vehículo de los saberes medicinales en una sociedad que dejaba de considerarse bárbara para sumarse al concierto de las naciones civilizadas. Desde la periferia americana se presentaban como discípulos de los conocimientos de las metrópolis europeas, por lo que advertía la posibilidad de que "si por más tiempo [tienen] las armas en las manos" se olvidaran los saberes y tuvieran que mendigarlos a los americanos. El olvido de distintos saberes en Europa, podía ser recuperado en América.

El 26 de agosto de 1801, Fernández encontró quien volviera a impugnar sus argumentos. Por varias semanas, se publicó una carta en el Telégrafo con el seudónimo de "Fortunato Titiro" que cuestionaba la descripción de las afueras de Montevideo y que no pusiera en perspectiva histórica sus críticas, ya que "sabe muy bien que desde la reciente época del comercio libre fue, únicamente, cuando Montevideo empezó a florecer. Entonces fue cuando se conoció el tesoro que contenían sus campos [...]" (TM, 1914, p. 397). La fundación de las parroquias quedó entonces centrada en las ciudades, porque sólo allí eran necesarias para los oficios religiosos. La educación para la civilidad se enmarcó en el nuevo rol de la iglesia para con sus feligreses. Del párroco como hombre de culto y de la liturgia del barroco se optó por la figura de un clérigo que fomentase la felicidad del pueblo, por lo que se ocuparían "[...] desde la creación de escuelas de primeras letras hasta la inoculación de la vacuna, desde la enseñanza de técnicas agrícolas «científicas» a los labradores de la feligresía [...] hasta la elaboración de informes sobre el estado demográfico y económico de la parroquia" (Di Stefano, 2000, p. 171). Apóstol de la vida racional y mediador entre culturas, el rol del párroco se alejaba de la liturgia para acercarse al modelo del pastor protestante por su función docente y de "cura de almas" (Di Stefano, 2000, p. 172). La preocupación en el Telégrafo sobre la educación moral y religiosa tenía su correlato en la figura del párroco ilustrado como agente "civilizador", por lo que la propuesta de la prensa se encontraba enmarcada en un imaginario que buscaba recubrir la vida cotidiana en el Buenos Aires tardocolonial.

\section{Cierre}

El Telégrafo se presentó como el remedio para curar la falta de civilidad entre los porteños. Su lectura era el tónico que necesitaban las mujeres, a las que se tildaba de irracionales, y los hombres, afectos a la desidia y al contrabando. El Semanario buscó con su escritura cambiar las costumbres de los campesinos, modernizar sus saberes experienciales gracias a la intervención del ciudadano patriota y el párroco ilustrado. La confianza en que la divulgación de las luces intervendría en las prácticas y estrategias de supervivencia de la campaña no 
dejaba de ser parte de las escenas ficcionales de lectura que se planteaban en la prensa. Los saberes impresos, que saldrían de los libros de la ciudad al campo gracias a la lectura en voz alta, eran signo de los nuevos tiempos ilustrados y por lo tanto, necesarios para lograr la "felicidad pública". Por ejemplo, frente a la salud pública se hizo hincapié en la necesidad de la vacunación antivariólica como muestra de civilidad y razón frente a las costumbres del pasado. La vacunación estaba avalada por los papeles que se publican por miles y que llegaban a las costas del Río de la Plata. La confianza en el progreso de las ciencias naturales se llevaba al mundo social. Si la vacunación permitía ganarle a la muerte, la literatura de civilidad podía inocular sus saberes ilustrados para que se cambien las costumbres.

La prensa no escapaba a su tiempo y la mujer era sinónimo de irracionalidad gobernada por los sentimientos. No se argumentaba contra las propuestas femeninas, simplemente se las acaballaba al catalogar sus dichos fuera de toda razón, principalmente por aventurarse al espacio público de la prensa. La élite letrada buscaba destacar aquellas acciones que la emparentaban a Europa y a la Corte de los Borbónes, pero también buscaba marcar las distancias de aquello que consideraba necesario cambiar para acceder al respeto de Europa. La identidad se jugaba en una doble oposición y diferenciación frente a la mirada extranjera, por ejemplo en la literatura de la historia natural (Maggio-Ramírez, 2019b).

El ciudadano patriota, al que apelaba Vieytes, era vecino de la ciudad y por lo tanto, contaba con un capital simbólico sobre cómo habitarla. Se lo buscó como mediador intercultural, capaz de llegar a los campesinos, no sólo porque frente a la ausencia de nobleza los vecinos de prestigio ocuparon ese lugar (Casanello, 2008) sino porque eran los principales suscriptores de los periódicos. Vieytes encontraba la ausencia de la civilidad en la campaña, mientras que Cabello y Mesa cuestionaba a los ciudadanos; por lo que al poco más de un año se le retiró el apoyo a su publicación. La élite letrada encontró en la civilidad un signo identificatorio para diferenciarse tanto de los campesinos como del bajo pueblo. En ese gesto, los letrados americanos validaron sus costumbres, en tanto estaban acorde a aquellas que circulaban en la prensa española, frente a la mirada europea que cuestionó a los americanos; por ejemplo en los escritos de Cornelius de Pauw.

\section{Bibliografía}

Andrés, J. (1784). Origen, progresos, y estado actual de toda la literatura. Madrid: Antonio de Sacha.

Arata, N. (2010). La enseñanza de los oficios mecánicos durante el Virreinato del Río de la Plata (1776-1810). Buenos Aires: Flacso. [https://www.ecys.flacso.org.ar/ensenanza-oficios-mecanicos Consultado, 22/1/2020]

Barral, M. E. (2007). Disciplina y civilidad en el mundo rural de Buenos Aires a fines de la Colonia. Jahrbuch für Geschichte Lateinamerikas = Anuario de Historia de América Latina (JbLA ), (44), 135-155.

Bolufer Peruga, M. (2002). Pedagogía y moral en el siglo de las Luces: Las escritoras francesas y su recepción en España. Revista de Historia Moderna. Anales de la Universidad de Alicante, 20. Recuperado de http://roderic.uv.es/han dle/10550/30342 [Consultado, 22/1/2020]

Bolufer Peruga, M. (2019). Arte y artificio de la vida en común: Los modelos de comportamiento y sus tensiones en el Siglo de las Luces. Madrid: Marcial Pons Historia.

Bustamante V., J. (2000). La escuela rural. Del Catón al arado. En C. A. Mayo (Ed.), Vivir en la frontera: La casa, la dieta, la pulpería, la escuela (1770-1870) (pp. 123-159). Buenos Aires: Biblos.

Caruso, M. A. (2010). La emancipación semántica: «primeras leteras» en Hispanoamérica (ca. 1770-1840). Bordón. Revista de pedagogía, 62 (2), 39-52.

Casanello, O. C. (2008). Ciudadano/Vecino. En N. Goldman (Ed.), Lenguaje y revolución: Conceptos politicos clave en el Río de la Plata, 1780-1850. Buenos Aires: Prometeo Libros.

Cucuzza, H. R. (2002). Leer y rezar en la Buenos Aires aldeana. En H. R. Cucuzza \& P. Pineau (Eds.), Para una historia de la enseñanza de la lectura y la escritura en Argentina. Del catecismo colonial a La Razón de Mi Vida. Buenos Aires: Miño y Dávila. 
Matías Maggio-Ramírez. La prensa de costumbres y la literatura de civilidad en la Buenos Aires tar...

Di Stefano, R. (2004). El púlpito y la plaza: Clero, sociedad y política de la monarquía católica a la república rosista. Buenos Aires, República Argentina: Siglo Veintiuno Editores Argentina.

Díaz, C. L. (2005). Intelectuales y periodismo: Debates públicos en el Rio de la Plata, 1776-1810. La Plata: Asociación Amigos del Archivo Histórico de la Provincia de Buenos Aires.

Furlong, G. (1944). Bibliotecas argentinas durante la dominación hispánica. Buenos Aires: Huarpes.

Goldgel, V. (2013). Cuando lo nuevo conquistó América: Prensa, moda y literatura en el siglo XIX. Buenos Aires: Siglo Veintiuno Editores.

Labrador Herráiz, C., \& Pablos Ramírez, J. C. de. (1989). La educación en los papeles periodicos de la Ilustracion Espanola. Madrid: Centro de Publ., Min. de Educación y Ciencia.

Lafit, F. (2017). Ilustración española y economía política en la prensa rioplatense tardocolonial. Anuario del Instituto de Historia Argentina, 17(1). https://doi.org/10.24215/2314257Xe039 [Consultado, 22/1/2020]

Maggio Ramírez, M. (2007). Nalgas sangrantes: Un boceto a mano alzada acerca de los problemas de hacer buena letra en la Buenos Aires colonial. Páginas de guarda: revista de lenguaje, edición y cultura escrita, 4, 107-114.

Maggio-Ramírez, M. (2008). Un puro vegetar. Representaciones de la lectura en el Semanario de Agricultura, Industria y Comercio. (1802-1806). En P. Brunetti, M. Maggio-Ramírez, \& M. del C. Grillo, Ensayos sobre la prensa: Primer Concurso de Investigación en Periódicos Argentinos en Homenaje al Prof. Jorge B. Rivera (pp. 205-292). Buenos Aires: Biblioteca Nacional.

Maggio-Ramírez, M. (2017). El Telégrafo Mercantil y el fomento de la civilidad. El nacimiento de la prensa de costumbres en el Buenos Aires virreinal. Historia y Comunicación Social, 22(1), 31-44. https://doi.org/10.520 9/HICS.55898 [Consultado, 22/1/2020]

Maggio-Ramírez, M. (2019). Civilidad a la mexicana. Lecturas de la Historia Antigua de México de Francisco Clavijero en la prensa virreinal de Buenos Aires (1801). Nueva Revista de Filología Hispánica (NRFH), 67(1), 105-130. h ttps://doi.org/10.24201/nrfh.v67i1.3466 [Consultado, 22/1/2020]

Maggio-Ramírez, M. (2019b). Un polemista sin contrincantes. La prosa americanista del poeta y dramaturgo Manuel José de Lavardén en el Semanario de Agricultura, Industria y Comercio. BOLETÍN AMERICANISTA, (78), 155-174. Recuperado de http://revistes.ub.edu/index.php/BoletinAmericanista/article/view/21491 [Consultado, 22/1/2020]

Maggio-Ramírez, M. (2020). La circulación de saberes y el problema de la autoría en la prensa virreinal. Un análisis del Correo de Comercio, 1810-1811, Información, Cultura y Sociedad, N. 42 [En prensa]

Martínez Gramuglia, P. (2010). A la búsqueda de lectores: El Telégrafo Mercantil. Question, 1(27). Recuperado de ht tp://perio.unlp.edu.ar/ojs/index.php/question/article/view/1000 [Consultado, 22/1/2020]

Martínez Gramuglia, P. F. (2009). El pensamiento agrario ilustrado en el Río de la Plata: Un estudio del Semanario de Agricultura, Industria y Comercio (1802-1807). Mundo agrario, 9(18). http://sedici.unlp.edu.ar/handle/10 915/13326, [Consultado, 22/1/2020]

Martini, M. P. (1998). Francisco Antonio Cabello y Mesa: Un publicista ilustrado de dos mundos (1786-1824). Buenos Aires: Instituto de Investigaciones sobre Identidad Cultural, Universidad del Salvador.

Moreno, J. L. (2004). Historia de la familia en el Río de la Plata. Buenos Aires: Editorial Sudamericana.

Navallo, T. (2011). La introducción a la Historia Natural de Tadeo Haenke y las representaciones de la naturaleza en la conformación del Alto Perú. Antítesis, 4, n 8 . Recuperado de http://www.uel.br/revistas/uel/index.php/an titeses/article/view/8160/9469

Pastore, R., \& Calvo, N. (2005). Ilustración y economía en el primer periódico impreso del Virreinato del Río de la Plata: El «Telégrafo Mercantil» (1801-1802). Bulletin hispanique, 107(2), 433-462.

Peire, J. (2008). Leer la Revolución de Mayo: Bibliotecas tardocoloniales en el Río de la Plata. Eadem Utraque Europa, $V I, 109-155$.

Piqueras Haba, J. (1991). El fomento de plantas textiles en la España ilustrada: Una visión espacial. Cuadernos de geografia, (50), 247-262. Recuperado http://mobiroderic.uv.es/handle/10550/27049 [Consultado, 22/1/20] 
Probst, J. (1924).Documentospara la Historia Argentina. Cultura: La enseñanza durante la época colonial\#: 1771 -1810 (Vol. 1-T. XVIII). Buenos Aires: Facultad de Filosofía y Letras, Universidad de Buenos Aires.

Semanario de Agricultura, Industria y Comercio. 1802-1803 (1928). Buenos Aires: Junta de Historia y Numismática Americana. [Reimpresión facsimilar, Vol. 1]

Rama, A. (1998). La ciudad letrada. Montevideo: Arca.

Sempere Guarinos, J. (1787). Ensayo de una biblioteca española de los mejores escritores del reynado de Carlos III, Madrid: Imprenta Real, 4. Recuperado de https://books.google.com.ar/ [Consultado, 22/1/20]

Telégrafo Mercantil: Rural, político-económico e historiógrafo del Río de la Plata [1 de abril al 27 de diciembre de 1801]. (1914). Buenos Aires: Junta de Historia y Numismática Americana. [Reimpresión facsimilar, Vol. 1 y 2]

Torre Revello, J. (1965). Bibliotecas en el Buenos Aires antiguo desde 1729 hasta la inauguracion de la Biblioteca Publica en 1812. Revista de Historia de América, (59), 1-148.

\section{NoTAS}

1 Entre los manuales que circularon por el virreinato de Buenos Aires pasaron desapercibidos para Portillo los de paleografía, que incluían en sus lecciones reglas corporales, morales y de higiene del aprendiz de pendolista. Ambrosio Funes, hermano del Deán Gregorio Funes, poseía en Córdoba "encuadernados en un solo volumen con el «ex-libris» de «Ambrosio Funes. Año 1792» en la primera página [...] las Láminas de las Reflexiones sobre el arte de escribir del Abate D. Domingo Ma. de Servidori, Madrid, Año 1789, y la Nueva Arte de escribir inventada con las magnificas láminas que en 1787 grabó Josef Ascencio" (Furlong, 1969, p. 92). Paleografía española, de Esteban de Terrero y Pando, impreso por Ibarra en 1758, fue uno de los libros fundacionales de la Biblioteca Pública de Buenos Aires, ya que perteneció al obispo Manuel Azamor Ramirez. Otro de los manuales hallados en la actual Biblioteca Nacional es el Arte de escribir, de Esteban Ximenez, que se publicó en 1789, donde se realizó un extracto o compendio de la obra Arte de escribir que Francisco Palomares publicó en 1776.

2 En dos pequeños párrafos del "Prospecto" se muestra el especial interés de Vieytes en la circulación del saber en favor de la prosperidad: "Pero ¿̇de qué utilidad podrá servir para el común de nuestros labradores el que un compatriota se forme en el silencio de su gabinete, que atesore sólo para sí, que no difunda y propague aquellos conocimientos que adquirió, y que unos libros tan útiles se hallen sólo circunscriptos a la pequeña esfera de un estante? [...] El habitador de la campaña debe esperar hoy más que nunca el ensanchar los estrechos límites de sus conocimientos mediante el interés que va a tomar el ciudadano instruido en enseñarle, al igual que el párroco, los preceptos más sencillos para mudar su triste situación".

3 Durante el siglo XVIII, España tuvo un fuerte aumento poblacional que implicó que las tierras dedicadas a las plantas textiles fueran reemplazadas por cultivos alimenticios como el trigo. También hubo una mayor demanda de lino y cáñamo, porque se necesitó una mayor cantidad de telas tanto para vestuario como para ropa de cama, así como para las actividades artesanales y marineras que necesitaban de sogas y velas. Campomanes también defendió el cultivo del lino y el cáñamo como una política en fomento de la industria popular, en tanto actividad complementaria de la agricultura para que el labrador se pudiera abastecer de la materia prima sin necesidad de acceder al comercio donde se hallaba la pieza terminada. Numerosos artículos en el Semanario de Agricultura y Artes dirigido a los párrocos abordaron en artículos y comentarios la importancia del lino y el cáñamo para la economía doméstica del labrador (Piqueras Habas, 1991, pp. 248-249)

4 Cabe recordar que una de las acepciones que tenía la palabra policía en 1780 para la RAE era: "La buena orden que se observa y se guarda en las ciudades y república cumpliendo las leyes, u ordenanzas establecidas para su mejor gobierno”. También se utilizaba como sinónimo de "Cortesía, buena crianza, urbanidad en el trato y costumbres. Urbanitas, comitas, morum elegantia, civilitas”, lo que implicaba la tercera acepción como “Aseo, limpieza, curiosidad y pulidez."

\section{BY-NC-SA}

